\title{
The Value of Cardiotrophin-1 in the Diagnosis, Severity, and Prognosis of Pulmonary Embolism
}

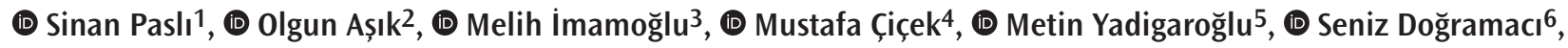 \\ (1) Ahmet Menteșe ${ }^{7}$, (1) Mürsel Șahin ${ }^{8}$, (1) Özgür Tatlı9
}

\author{
${ }^{1}$ Gümüșhane State Hospital, Clinic of Emergency Medicine, Gümüșhane, Turkey \\ 2University of Health Sciences Turkey, Trabzon Kanuni Training and Research Hospital, Clinic of Emergency Medicine Trabzon, Turkey \\ 3 Rize State Hospital, Clinic of Emergency Medicine, Rize, Turkey \\ ${ }^{4}$ Bayburt State Hospital, Clinic of Emergency Medicine, Bayburt, Turkey \\ ${ }^{5}$ Fatih State Hospital, Clinic of Emergency Medicine, Trabzon, Turkey \\ 6Karadeniz Technical University, Faculty of Medicine, Department of Medical Biochemistry, Trabzon, Turkey \\ ${ }^{7}$ Karadeniz Technical University, Health Services Vocational School, Program of Medical Laboratory Techniques, Trabzon, Turkey \\ ${ }^{8}$ Karadeniz Technical University, Faculty of Medicine, Department of Cardiology, Trabzon, Turkey \\ ${ }^{9}$ Karadeniz Technical University, Faculty of Medicine, Department of Emergency Medicine, Trabzon, Turkey
}

\begin{abstract}
Aim: Pulmonary embolism (PE) is a life-threatening condition that requires early diagnosis and treatment. There is still a need for precise and non-invasive biomarkers that can be used to diagnose PE. This study aimed to determine the diagnostic value of Cardiotrophin-1 (CT-1) in patients with acute PE and ascertain the relationship between serum CT-1 level and disease prognosis and severity.

Materials and Methods: In this prospective study, the serum CT-1 levels of 165 patients with suspected acute PE were measured. The patients were divided into two groups, PE (+) and PE (-), based on their computed tomography angiography results. Their serum CT- 1 levels were compared.

Results: The CT-1 levels of the PE $(+)$ group (median $=4.18 \mathrm{pg} / \mathrm{mL}$, range $=3.57-9.55 \mathrm{pg} / \mathrm{mL}$ ) was non-significantly $(\mathrm{p}=0.08)$ different from those of the PE (-) group (median=4.38 pg/mL, range $=3.57-51.64 \mathrm{pg} / \mathrm{mL}$ ). Based on the severity of the condition, there were significant differences $(p=0.001)$ in the CT-1 levels of the patients in the intermediate-low risk group (median=4.19 $\mathrm{pg} / \mathrm{mL}, \mathrm{range}=3.62-5.32 \mathrm{pg} / \mathrm{mL}$ ), intermediate-high risk group (median $=4.06 \mathrm{pg} / \mathrm{mL}$, range $=3.57-9.31 \mathrm{pg} / \mathrm{mL}$ ) and high risk group (median=5.01 pg/mL, range $=3.89-9.55 \mathrm{pg} /$ $\mathrm{mL}$ ). Based on the clinical course, the CT-1 levels of the patients in the good clinical course group (median=4.15 pg/mL, range $=3.57-9.31 \mathrm{pg} /$ $\mathrm{ml}$ ) were significantly different $(\mathrm{p}=0.004)$ from those in the poor clinical course group (median=4.53 pg/mL, range=3.66-9.55 pg/mL).

Conclusion: CT-1 level was not observed to be a precise biomarker for the diagnosis of acute PE. However, our study demonstrated that the serum CT-1 levels can be used as a biomarker for ascertaining the severity and prognosis of patients with PE.
\end{abstract}

Keywords: Pulmonary embolism, diagnosis, severity, prognosis, Cardiotrophin-1

\section{Introduction}

Pulmonary embolism (PE) is a common and potentially lifethreatening clinical condition that may cause obstruction of the pulmonary vascular bed and concomitant right heart failure $(1,2)$. Early diagnosis and treatment can be life-saving. Currently, there are still various difficulties in the diagnosis of PE in emergency departments due to nonspecific symptoms and signs. D-dimer is a marker with high negative and low positive predictive value that can be used non-invasively in the diagnosis of PE. Definitive diagnosis is made by expensive techniques such as pulmonary scintigraphy and spiral computed tomography (CT) or invasive methods such as pulmonary angiography (3). However, these invasive and expensive methods may not always be available. 
There is still a need for easy and non-invasive alternative biomarkers that can be used to diagnose PE and determine its severity and prognosis. Several guidelines recommend modified Well's Score (mWS) for assessing PE risk levels for patients without clinically shock findings. According to mWS, D-Dimer, CT anjiography (CTA) and bedside echocardiography are the choices of diagnostic tools. There are advantages and disadvantages of both CTA and echocardiography. The latter is non-invasive and can be performed at the bedside, while its major disadvantages are that it is userdependent and is not as sensitive and specific as CTA (3).

PE may follow an asymptomatic course, or may also result in severe right ventricular failure, hypotension, shock, and arrest. It is known that there is a strong relationship between the severity of PE and prognosis. The use of thrombolytic therapy in haemodynamically stable patients with PE causing RVD is still controversial. Studies in which thrombolytic therapy administered to the patients with moderate-risk PE, defined as patients with RVD findings and with high biochemical parameters such as Troponin (Tn) or B-type Natriuretic Peptide (BNP), proBNP, heart type fatty acid-binding protein (H-FABP) despite not being hypotensive, have shown that such treatment has positive effects on preventing the development of haemodynamic decompensation (4). Biochemical parameters therefore also play a role, in addition to echocardiography and $\mathrm{CT}$, in determining the severity and prognosis of PE (1). There are prognostic models such as the PE Severity index (PESI) or simplified PESI (SPESI), established using the clinical features of the patients at presentation $(5,6)$. These models are used to determine the risk of early mortality in patients with confirmed diagnosis of acute PE by evaluating imaging results together with other clinical findings (1). In addition, they can also assist clinicians in the decision whether to admit patients with acute PE or observe them on an outpatient basis (7).

CT-1, a novel biochemical marker, is a $21.5 \mathrm{kDa}$ protein from the interleukin-6 family, containing 201 amino acids and found in human heart, lung, and skeletal muscle. This cytokine performs transmembrane signaling through the glycoprotein 130 receptor. It has been shown to exhibit a powerful protective and hypertrophic effect on cardiac myocytes $(8,9)$. CT-1 has also been shown to be of prognostic and diagnostic value in several cardiovascular diseases, such as hypertension, congestive heart failure, acute myocardial infarction, and valvular heart disease (10). It is probable that CT-1 levels may play a role in the diagnosis of PE and also it may be useful to determine the prognosis and the severity.

\section{Materials and Methods}

Approval for this prospective, randomized clinical study was granted by the Karadeniz Technical University Scientific
Researches Ethical Committee (no: 2016/7). The study was performed in the Karadeniz Technical University School of Medicine Department of Emergency Medicine, a tertiary centre serving approximately 100,000 patients a year.

\section{Selection of Participants}

In the one-year period following receipt of ethical committee approval, patients aged over 18, consenting to take part and presenting to the emergency department with suspected acute PE and undergoing CTA were included in the study. Patients with kidney failure or advanced liver failure at time of presentation, pregnant women, and patients with deficient records were excluded.

\section{Study Design and Setting}

The diagnostic algorithm specified in the 2014 European Society of Cardiology (ESC) guidelines on the diagnosis and management of PE was used to evaluate the patients presenting to the emergency department on suspicion of acute PE. Consistent with that algorithm, patients undergoing spiral CTA (Siemens Somatom Sensation, Germany) and identified as having PE were included in the PE (+), and those without PE were enrolled in the PE (-) group. The diagnostic value of CT-1 was then investigated. In addition, patients diagnosed with acute PE were classified as low risk, intermediate-low risk, intermediate-high risk, and high risk based on early mortality classification as described in the 2014 ESC guidelines on the diagnosis and management of PE. Analysis of CT-1 and other biochemical parameters was then performed among these groups. Finally, all patients in the PE $(+)$ group was followed-up for 90 days and prognostic analysis was performed according to defined clinical endpoints: intensive care requirements, intubation and mechanical ventilation requirements, vasopressor requirements, cardiopulmonary resuscitation and mortality. Patients developing one of these clinical end points were classified as the poor clinical course group, while those not developing any of the clinical endpoints were classified as the good clinical course group, and the prognostic value of CT-1 measured at time of presentation in acute PE patients was investigated. Informed consent was obtained from all patients included in the study.

\section{Biochemical Measurements}

Blood specimens were placed into gel separator blood tubes and allowed to clot for $20 \mathrm{~min}$ at room temperature. The tubes were then centrifuged at 1800xg for 10 min. Following centrifugation, the serum was carefully transferred to small, closed tubes and stored at $-80^{\circ} \mathrm{C}$ until the day of study.

Serum specimen CT-1 levels were measured using an enzymelinked immunosorbent assay (ELISA) kit (BioVendor, Cat 
No: RD192026200CS, Brno, Czech Republic) in line with the manufacturer's instructions. The results were expressed as pg/ $\mathrm{mL}$. The intra-assay repeatability of this method was $4.4 \%$ (CV\%).

\section{Statistical Analysis}

Statistical analysis was performed on SPSS 23.0 (IBM SPSS, Armonk, NY, USA) and MedCalc 12.3 (MedCalc Software, Mariakerke, Belgium) statistical software. Compatibility with normal distribution was assessed using the Shapiro-Wilk test. The Mann-Whitney U test was applied to compare the PE (+) and PE (-) groups. $p$ values $<0.05$ were regarded as statistically significant. To determine the accuracy and respective best cut-off values of $\mathrm{CT}-1$ for predicting APE, the receiver operating characteristic (ROC) curves and their corresponding areas under the curve were used. A p value of $<0.05$ was considered statistically significant.

\section{Outcomes}

The primary aim of this study was to investigate the value of CT-1 in the diagnosis of PE. Our secondary aim was to determine the value of CT-1 in determining the severity of PE using CT and echocardiography findings and Tn levels. We also investigated whether $\mathrm{CT}-1$ is of any value in showing prognosis in PE patients.

\section{Results}

During the study period 221 patients presenting with suspected acute PE to emergency department were evaluated. Twentyseven patients were excluded for not meeting the inclusion criteria. CTA was not performed on seven patients due to findings of right ventricular dysfunction (RVD) at echocardiography, and these were also excluded. Another four patients were excluded since CTA could not be performed due to instability. CTA was also not performed on 18 patients in the low risk group based on clinical probability analysis and with negative D-dimer results. Information about the patients included in and excluded from the study is shown in Figure 1. CTA was finally performed on 165 patients, 67 were in acute PE group, and 98 in the non-acute PE group. A comparison of the two groups' basic clinical and demographic characteristics is shown in Table 1. No statistically significant difference was determined between the two groups' demographic and clinical characteristics ( $p>0.05$ for all).

Since the primary aim of this study was to determine the diagnostic value of CT-1 in PE, acute PE and non-PE groups were compared in terms of CT-1 and other biochemical parameters. Median CT-1 values were $4.38 \mathrm{pg} / \mathrm{mL}$ (3.57-51.64) in the non-PE group and $4.18 \mathrm{pg} / \mathrm{mL}$ (3.57-9.55) in the acute PE group. These results revealed no statistically significant difference between the two groups in terms of CT-1 values at time of presentation $(p=0.08)$. Comparisons of other biochemical markers between the two groups revealed significant differences in terms of TnT-hs, D-dimer, WBC and pCO2 levels ( $p=0.004, p=<0.0001$, $p=0.022$, and $p=0.002$, respectively). Biochemical parameters between the acute PE and non-PE groups are shown in Table 2. ROC curve analysis was performed for CT-1 in patients diagnosed with APE and the area under the curve was found to be 0.581 ( $p=0.071 ; 95 \%$ Cl 54,6 to 74,4 Figure 2). The best cut-off values for CT-1 when predicting APE in patients with clinically suspected APE presenting at the ED were $4.2 \mathrm{pg} / \mathrm{mL}$ (sensitivity 54.5\%; specificity $64.9 \%)$.

The secondary aim of this study was to determine the value of CT-1 in determining the severity of PE in patients diagnosed with the condition. For that purpose, we compared CT-1 and other biochemical parameters between the intermediate-low, intermediate-high and high-risk groups previously established. since there were no patients in the low-risk group, this could not be included in the analysis. Median CT-1 values were 4.19 $\mathrm{pg} / \mathrm{mL}$ (3.62-5.32) in the intermediate-low risk group, $4.06 \mathrm{pg} /$ $\mathrm{mL}$ (3.57-9.31) in the intermediate-high risk group, and 5.01 $\mathrm{pg} / \mathrm{mL}$ (266.5-1435.1) in the high-risk group. Analysis revealed significant differences in terms of CT- 1 values among the three

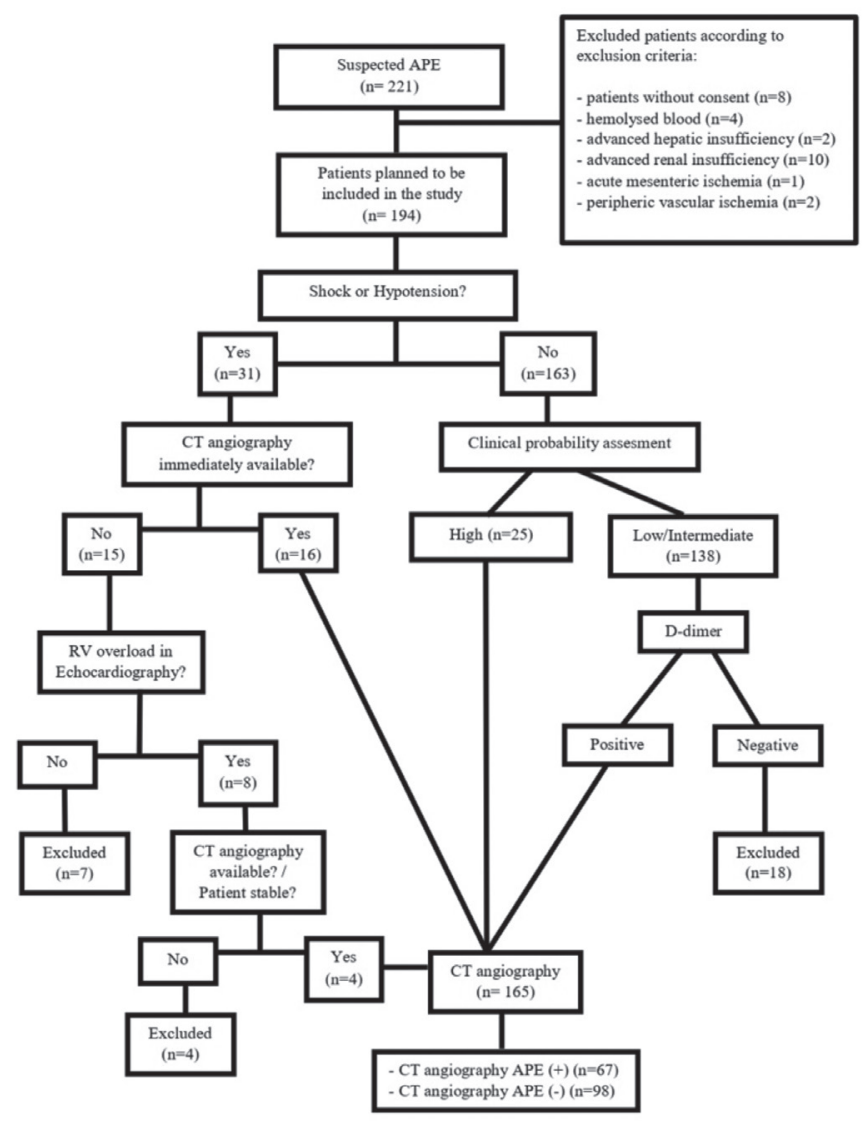

Figure 1. Study flow chart

CT: Computed tomography, APE: Acute pulmonary embolism, $\mathrm{n}$ : Number 


\begin{tabular}{|c|c|c|c|}
\hline & $\begin{array}{l}\text { APE Negative, } \\
\mathbf{n}(\%)\end{array}$ & $\begin{array}{l}\text { APE Positive, } \\
\text { n (\%) }\end{array}$ & p \\
\hline Age, med (min-max) & $72.5(18-96)$ & 78 (38-95) & 0.69 \\
\hline \multicolumn{4}{|l|}{ Gender } \\
\hline Female & $55(33.3 \%)$ & $43(27.3 \%)$ & \multirow[t]{2}{*}{0.194} \\
\hline Male & $45(26.1 \%)$ & $22(13.3 \%)$ & \\
\hline \multicolumn{4}{|l|}{ Symptom } \\
\hline Dyspnea & $82(49.7 \%)$ & $55(33.3 \%)$ & 0.834 \\
\hline Chest pain & $24(14.5 \%)$ & $17(10.3 \%)$ & 1.0 \\
\hline Hemoptysis & $4(2.4 \%)$ & $3(1.8 \%)$ & 1.0 \\
\hline Syncope & $16(9.7 \%)$ & $16(9.7 \%)$ & 0.237 \\
\hline DVT symptoms & $3(1.8 \%)$ & $6(3.6 \%)$ & 0.161 \\
\hline Other symptoms & $27(16.4)$ & $23(13.9 \%)$ & 0.391 \\
\hline \multicolumn{4}{|l|}{ Vitals } \\
\hline $\begin{array}{l}\text { SBP mmHg, mean } \pm \\
\text { SD }\end{array}$ & $118.57 \pm 23.9$ & $117.08 \pm 24.4$ & 0.649 \\
\hline $\begin{array}{l}\text { DBP mmHg, med (min- } \\
\max )\end{array}$ & $71.5(40-140)$ & $72(40-120)$ & 0.831 \\
\hline Pulse/min, mean \pm SD & $101.94 \pm 23.3$ & $98.65 \pm 21.9$ & 0.320 \\
\hline $\begin{array}{l}\text { Respiratory rate/min, } \\
\text { med (min-max) }\end{array}$ & $22(10-45)$ & $24(10-42)$ & 0.257 \\
\hline $\begin{array}{l}\text { Body temperature }{ }^{\circ} \mathrm{C}, \\
\text { med (min-max) }\end{array}$ & $36.7(35.9-39.5)$ & $36.8(36-39.2)$ & 0.697 \\
\hline \multicolumn{4}{|l|}{ ECG findings } \\
\hline S1Q3T3 & $4(2.4 \%)$ & $4(2.4 \%)$ & 0.716 \\
\hline Sinus tachicardia & $28(17.0 \%)$ & $24(14.5 \%)$ & 0.394 \\
\hline Atrial fibrillation & $24(14.5 \%)$ & $16(9.7 \%)$ & 1.0 \\
\hline Negative T waves & $13(7.9 \%)$ & $17(10.3 \%)$ & 0.64 \\
\hline RBBB & $0(0.0 \%)$ & $3(1.8 \%)$ & 0.65 \\
\hline \multicolumn{4}{|l|}{ X-ray findings } \\
\hline Pleural effusion & $20(12.1 \%)$ & $9(5.5 \%)$ & 0.301 \\
\hline Atelectasia & $23(13.9 \%)$ & $13(7.9 \%)$ & 0.57 \\
\hline Diaphragm elevation & $2(1.2 \%)$ & $5(3.0 \%)$ & 0.121 \\
\hline Hampton hump & $1(0.6 \%)$ & $0(0.0 \%)$ & 1.0 \\
\hline $\begin{array}{l}\text { Pulmonary artery } \\
\text { dilatation }\end{array}$ & $9(5.5 \%)$ & $4(2.4 \%)$ & 0.453 \\
\hline \multicolumn{4}{|l|}{ VTE risk factors } \\
\hline Previous PE & $6(3.6 \%)$ & 10 (6.1\%) & 0.105 \\
\hline Previous DVT & $4(2.4 \%)$ & $4(2.4 \%)$ & 0.716 \\
\hline Varicose veins & $3(1.8 \%)$ & $4(2.4 \%)$ & 0.443 \\
\hline $\begin{array}{l}\text { Chronic venous } \\
\text { insufficiency }\end{array}$ & $1(0.6 \%)$ & $0(0.0 \%)$ & 1.0 \\
\hline Previous stroke & $14(8.5 \%)$ & $11(6.7 \%)$ & 0.826 \\
\hline
\end{tabular}

\begin{tabular}{|c|c|c|c|}
\hline Pregnancy & $0(0.0 \%)$ & $0(0.0 \%)$ & 1.0 \\
\hline Malignancy & $29(17.6 \%)$ & $25(15.2 \%)$ & 0.315 \\
\hline Obesity & $12(7.3 \%)$ & $13(7.9 \%)$ & 0.269 \\
\hline Smoking history & $12(7.3 \%)$ & $11(6.7 \%)$ & 0.496 \\
\hline Immobilisation & $38(23.0 \%)$ & $35(21.2 \%)$ & 0.111 \\
\hline Surgery in 4 weeks & $6(3.6 \%)$ & $7(4.2 \%)$ & 0.362 \\
\hline Trauma in 4 weeks & $4(2.4 \%)$ & $5(3.0 \%)$ & 0.488 \\
\hline Coagulopathy & $1(0.6 \%)$ & $1(0.6 \%)$ & 0.406 \\
\hline $\begin{array}{l}\text { Oral contraceptive } \\
\text { use }\end{array}$ & $0(0.0 \%)$ & $0(0.0 \%)$ & 1.0 \\
\hline Postpartum period & $0(0.0 \%)$ & $1(0.6 \%)$ & 0.406 \\
\hline
\end{tabular}

\section{CT-1}

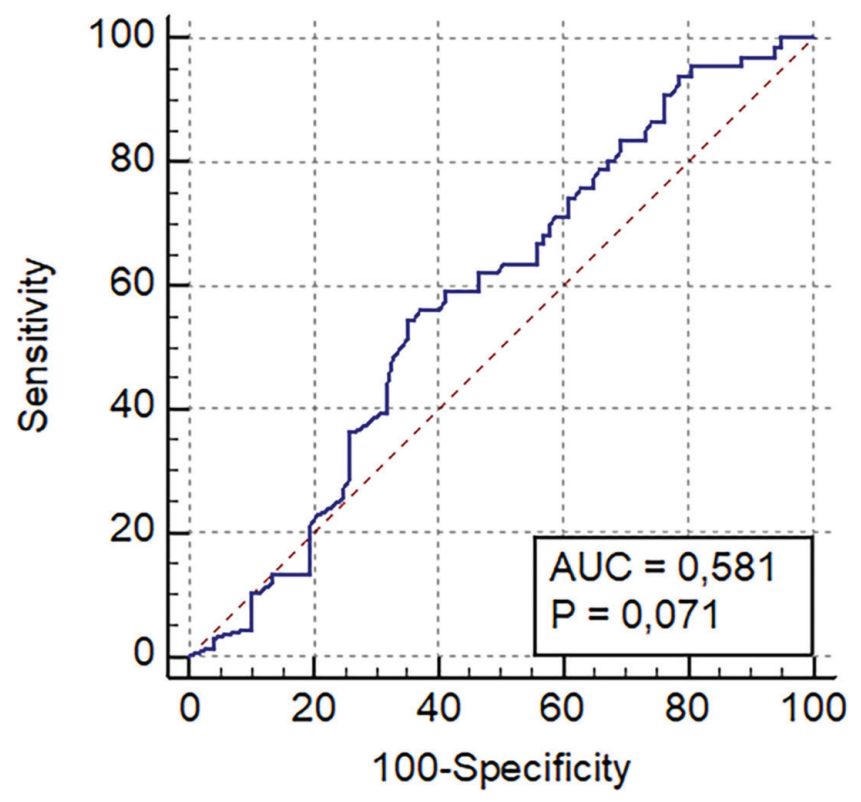

Figure 2. Roc curve analysis

AUC: Area under the curve, CT-1: Cardiotrophin-1

groups $(p=0.001)$. Bonferroni correction was used in twoway comparisons between groups and showed a significant difference between the high-risk group and the intermediatelow and intermediate-high risk groups (Bonferroni test $p=0.002$ and $p=0.001$, respectively). CT-1 level in these three groups are shown in Figure 3.

Comparisons among these three groups in terms of other biochemical parameters revealed statistically significant differences in Tn-T and proBNP values $(p=0.044$, and $p=0.016$, respectively), but none in terms of the other biochemical 
parameters. Comparisons using Bonferroni correction revealed a significant difference in pro-BNP between the intermediatelow risk group and the intermediate-high risk group $(p=0.005)$. A comparison of biochemical parameters among the three groups constituted to determine the severity of PE is shown in Table 3.

For the third aim of this study, to evaluate the prognostic value of CT-1 in patients with PE, comparison of biochemical values in the good and poor clinical course groups that established according

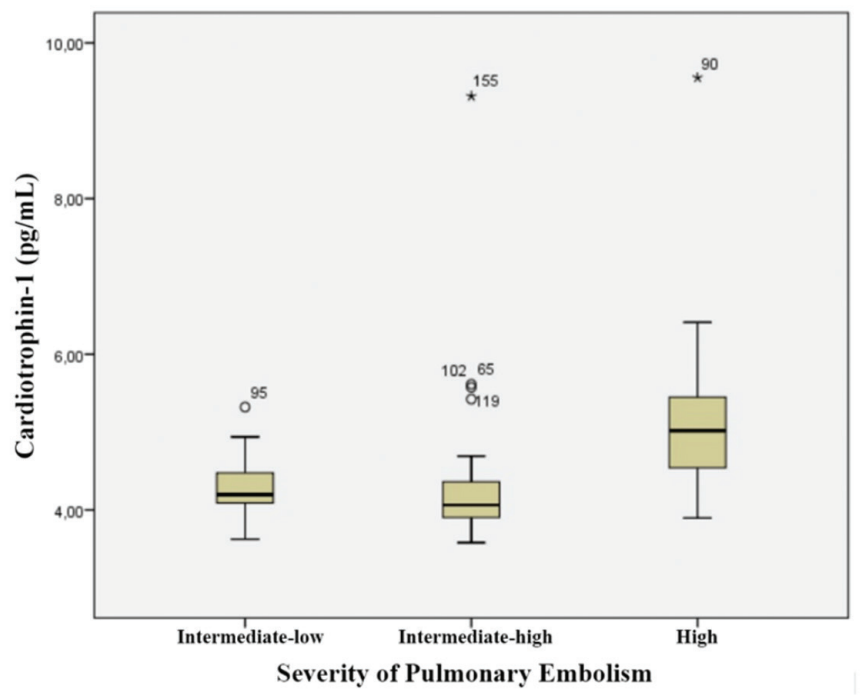

Figure 3. Distribution of Cardiotrophin-1 levels in the PE severity groups PE: Pulmonary embolism to previously mentioned was performed. Median CT-1 values were $4.15 \mathrm{pg} / \mathrm{mL}$ (3.57-9.31) in the good clinical course group and $4.53 \mathrm{pg} / \mathrm{mL}$ (3.66-9.55) in the poor clinical course group and a statistically significant difference was found between the two groups $(p=0.004)$. CT-1 values between the groups evaluated in terms of prognosis are shown in Figure 4. The analysis of other biochemical parameters between two groups showed a significant difference only in terms of Tn-T $(p=0.008)$. The

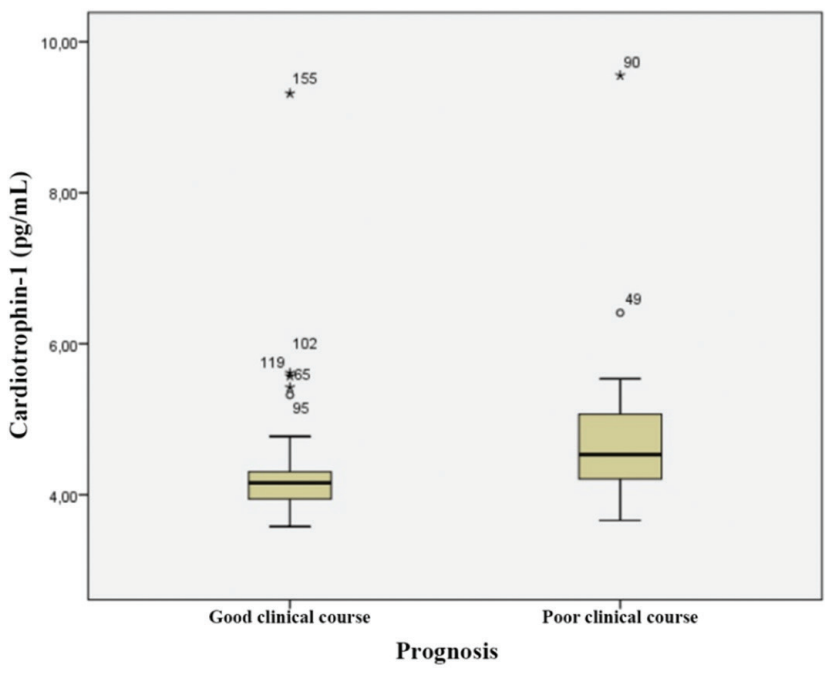

Figure 4. Comparison of biochemical parameters among the acute PE clinical course groups

PE: Pulmonary embolism

\begin{tabular}{|c|c|c|c|}
\hline Marker & $\begin{array}{l}\text { PE negative } \\
(n=98)(59.4 \%)\end{array}$ & $\begin{array}{l}\text { PE positive } \\
(n=67)(40.6 \%)\end{array}$ & $\mathbf{p}$ \\
\hline CT-1 (pg/mL), med (min-max) & $4.38(3.57-51.64)$ & $4.18(3.57-9.55)$ & 0.080 \\
\hline TnT-hs (ng/L), med (min-max) & $27.14(3.18-6676.0)$ & $38.64(3.0-315.8)$ & 0.004 \\
\hline CK-MB (ng/L), med (min-max) & $1.905(0.3-38.62)$ & $2.29(0.32-13.69)$ & 0.302 \\
\hline Ph, med (min-max) & $7.45(6.82-7.67)$ & $7.45(7.05-7.57)$ & 0.414 \\
\hline $\mathrm{pCO}_{2}(\mathrm{mmHg})$, med (min-max) & $34.85(17.0-74.3)$ & $31.3(15.2-61.0)$ & 0.002 \\
\hline $\mathrm{pO}_{2}(\mathrm{mmHg})$, med (min-max) & $71.3(38.9-177.0)$ & $71.3(44.5-166.0)$ & 0.758 \\
\hline $\mathrm{sO}_{2}(\%)$, med (min-max) & $93.45(56.3-99.0)$ & 92.8 (72.9-99.3) & 0.459 \\
\hline Glucose (mg/dL), med (min-max) & 131 (78-393) & $129(90-498)$ & 0.897 \\
\hline BUN (mg/dL), med (min-max) & $21.5(6.0-87.0)$ & $23.0(6.0-92.0)$ & 0.386 \\
\hline Creatinine (mg/dL), med (min-max) & $0.9(0.23-2.39)$ & $0.9(0.43-1.74)$ & 0.470 \\
\hline $\operatorname{ALT}(\mathrm{U} / \mathrm{L})$, med (min-max) & $19.5(3.0-396.0)$ & $15.0(3.0-199.0)$ & 0.128 \\
\hline AST (U/L), med (min-max) & $30.0(9.0-285.0)$ & $25.0(10.0-531.0)$ & 0.124 \\
\hline D-dimer ( $\mu \mathrm{g} / \mathrm{mL})$, med (min-max) & $2.71(0.57-40.0)$ & $7.54(1.11-42.92)$ & $<0.0001$ \\
\hline CRP (mg/dL), med (min-max) & $4.97(0.13-37.28)$ & $7.0(0.2-36.29)$ & 0.448 \\
\hline $\mathrm{WBC}(/ \mu \mathrm{L})$, med (min-max) & $7860(180-168000)$ & $10630(1120-38340)$ & 0.022 \\
\hline
\end{tabular}


comparison of biochemical markers between the two groups is shown in Table 3.

\section{Discussion}

Acute PE is a common acute cardiovascular disease. However, diagnosis of patients presenting with acute PE can be difficult (11). Since mortality decreases significantly in cases that are treated early, rapid diagnosis is particularly important in this clinical condition with high mortality and morbidity.

Several biochemical markers and parameters have been investigated in the diagnosis of PE but to the best of our knowledge, this is the first study to evaluate the prognostic value of Cardiotrophin-1 (CT-1) in the diagnosis of PE. In this study, we also evaluated the relationship between the serum CT-1 levels with the prognosis and the risk levels of the disease.

CT-1 is a survival promoting cytokine detected in cardiomyocytes and cardiac fibroblasts in response to mechanical, humoral, metabolic and hypoxic stress. In acute stress conditions, CT-1 increases cell survival, whereas in increased stress states, the chronic effect of CT-1 is cardiomyocyte hypertrophy and consequently left ventricular failure (12). CT-1 is also released from vascular endothelial cells and produces direct vascular effects in the form of atherogenesis, vascular dysfunction, arterial stiffness and increased blood pressure $(13,14)$. Overall, CT-1 is an effective profibrotic agent for the heart and vessels $(12,14)$. In a review Calabrò et al. (15) evaluated the role of CT-1 in cardiovascular diseases and said that, plasma CT-1 levels are higher in patients with hypertension (with left ventricular hypertrophy), significant mitral regurgitation (with left ventricular function), aortic stenosis, unstable angina, acute myocardial infarction, and heart failure than healthy subjects.
Although it may be a biochemical marker that can be used as a diagnostic tool in cardiovascular diseases, because of the low specifity and the sensitivity rates, we concluded that CT-1 alone will not be useful in the diagnosis of acute PE. And we found that among other biochemical parameters, TnT-hs and D-dimer levels were higher in the PE group, consistent with the literature. It is well known that elevated plasma troponin levels are associated with worse prognosis in PE (1). But the use of plasma troponin levels alone in the diagnosis of $\mathrm{PE}$ is not appropriate because plasma troponin levels are elevated in many different cardiovascular diseases and may cause errors in diagnosis. Also, D-Dimer has a high negative and low positive predictive value, and it is used in the primary evaluation of the PE in suspected patients.

The use of cardiac troponin levels to assess the severity of PE is recommended by the 2019 ESC guideline. In addition to this, increased Heart-type fatty acid-binding protein (H-FABP), BNP, $\mathrm{N}$-terminal (NT) proBNP and lactate levels were reported to be associated with poor prognosis in PE (1). Hellenkamp et al. (16) investigated the effect of copeptin on the prognosis of PE and found that patients with high levels of copeptin had more adverse outcomes. It was said that copeptin levels could improve risk stratification in normotensive patients if it was integrated in the risk assessment algorithm in the 2014 ESC algorithm. In our study we found that CT-1 levels were higher in the high-risk group compared to intermediate-high risk and intermediatelow risk groups. According to these findings we can say that CT-1 levels can be used to identify high risk PE patients. We also found that CT-1 levels are higher in the previously defined poor clinical course group and higher CT-1 levels are associated with poor prognosis.

\begin{tabular}{|c|c|c|c|c|c|c|c|}
\hline \multirow[t]{2}{*}{ Marker } & \multicolumn{4}{|c|}{ PE severity groups } & \multicolumn{3}{|c|}{ Acute PE clinical course groups } \\
\hline & $\begin{array}{l}\text { Intermediate- } \\
\text { low risk } \\
(n=23)(\% 34.3)\end{array}$ & $\begin{array}{l}\text { Intermediate-high risk } \\
(\mathrm{n}=32)(\% 47.8)\end{array}$ & $\begin{array}{l}\text { High risk } \\
(n=12)(\% 17.9)\end{array}$ & $p$ & $\begin{array}{l}\text { Good clinical course } \\
(n=44)(\% 65.7)\end{array}$ & $\begin{array}{l}\text { Poor clinical } \\
\text { course } \\
(n=23)(\% 34.3)\end{array}$ & $p$ \\
\hline $\begin{array}{l}\text { CT-1 (pg/mL), } \\
\text { med (min-max) }\end{array}$ & $\begin{array}{l}4.19 \\
(3.62-5.32)\end{array}$ & $\begin{array}{l}4.06 \\
(3.57-9.31)\end{array}$ & $\begin{array}{l}5.01 \\
(3.89-9.55)\end{array}$ & 0.001 & $\begin{array}{l}4.15 \\
(3.57-9.31)\end{array}$ & $\begin{array}{l}4.53 \\
(3.66-9.55)\end{array}$ & 0.004 \\
\hline $\begin{array}{l}\text { D-dimer }(\mu \mathrm{g} / \mathrm{mL}) \text {, } \\
\text { med (min-max) }\end{array}$ & $\begin{array}{l}7.54 \\
(1.11-30.0)\end{array}$ & $\begin{array}{l}9.54 \\
(1.25-39.41) \\
\end{array}$ & $\begin{array}{l}5.72 \\
(1.59-42.93)\end{array}$ & 0.821 & $\begin{array}{l}8.22 \\
(1.11-30.0)\end{array}$ & $\begin{array}{l}7.49 \\
(1.59-42.93) \\
\end{array}$ & 0.235 \\
\hline $\begin{array}{l}\text { TnT-hs (ng/L), } \\
\text { med (min-max) }\end{array}$ & $\begin{array}{l}34.16 \\
(3.00-197.00)\end{array}$ & $\begin{array}{l}37.46 \\
(15.39-226.50)\end{array}$ & $\begin{array}{l}65.22 \\
(14.80-315.80)\end{array}$ & 0.044 & $\begin{array}{l}35.0 \\
(3.0-208.20)\end{array}$ & $\begin{array}{l}67.0 \\
(12.92-315.80)\end{array}$ & 0.008 \\
\hline $\begin{array}{l}\text { Nt-proBNP }(\mathrm{pg} / \mathrm{mL}) \text {, } \\
\text { med (min-max) }\end{array}$ & $\begin{array}{l}789.0 \\
(71.0-12172.0)\end{array}$ & $\begin{array}{l}2686.5 \\
(80.0-18691.0)\end{array}$ & $\begin{array}{l}3861.0 \\
(178.0-17647.0)\end{array}$ & 0.016 & $\begin{array}{l}1833.50 \\
(71.0-18691.0)\end{array}$ & $\begin{array}{l}1849.20 \\
(147.0-17647.0)\end{array}$ & 0.607 \\
\hline
\end{tabular}

PE: Pulmonary embolism, CT-1: Cardiotrophin-1, TnT-hs: High sensitive cardiac troponin T, Nt-proBNP: N terminal prohormone of B-type natriuretic peptide, min: Minimum, max: Maximum, med: Median, $\mathrm{n}$ : Number 


\section{Study Limitations}

When our study was conducted, since the 2019 ESC guideline has not yet been published and the valid guideline for PE was the 2014 ESC guideline, we used the 2014 ESC guideline to determine the patient inclusion criteria and PE severity classification and algorithm.

The major limitation of this study is that the time of onset of PE was unclear, and that since time of presentation to hospital differed for all patients, serum collection times could not be standardized for all individuals.

Another important limitation of this study is that blood was collected from patients presenting with suspected PE only at time of presentation, rather than periodically, and no analysis of time-dependent changes in CT-1 levels was possible.

\section{Conclusion}

The results of this study do not support the use of CT-1 as a diagnostic marker in acute PE patients. However, they do suggest that serum CT-1 may be useful in determining clinical severity and prognosis in patients with acute PE.

\section{Ethics}

Ethics Committee Approval: Approval for this prospective, randomized clinical study was granted by the local clinical research ethical committee (no: 2016/7).

Informed Consent: Informed consent was obtained from the patients.

Peer-review: Externally peer-reviewed.

\section{Authorship Contributions}

Surgical and Medical Practices: S.P., O.A., M.I., Concept: S.P., O.A., M.I., A.M., M.S., Ö.T., Design: S.P., O.A., M.I., A.M., M.S., Ö.T., Data Collection or Processing: S.P., O.A., M.C.., M.Y., Analysis or Interpretation: M.C.., M.Y., S.D., A.M., Ö.T., Literature Search: S.P., O.A., M.I., Writing: S.P., O.A., M.I.

Conflict of Interest: The authors declare that they have no significant competing financial, professional or personal interests that might have influenced the performance or presentation of the work described in this manuscript.

Financial Disclosure: The study was supported by the Karadeniz Technical University Scientific Research Projects Unit.

\section{References}

1. Konstantinides SV, Meyer G, Becattini C, Bueno H, Geersing GJ, Harjola VP, et al. 2019 ESC Guidelines for the diagnosis and management of acute pulmonary embolism developed in collaboration with the European Respiratory Society (ERS). Eur Heart J. 2020;41:543-603.

2. Ribeiro A, Juhlin-Dannfelt A, Brodin LA, Holmgren A, Jorfeldt L. Pulmonary embolism: relation between the degree of right ventricle overload and the extent of perfusion defects. Am Heart J. 1998;135:868-74.

3. Stein PD, Hull RD, Patel KC, Olson RE, GhaliWA, Brant R, et al. D-dimer for theexclusion of acute venous thrombosis and pulmonary embolism: a systematic review. Ann Intern Med. 2004;140;589:602-51.

4. Meyer G, Vicaut E, Danays T, Agnelli G, Becattini C, Beyer-Westendorf J, et al. Fibrinolysis for patients with intermediate-risk pulmonary embolism. N Engl J Med. 2014;370:1402-11.

5. Aujesky D, Obrosky DS, Stone RA, Auble TE, Perrier A, Cornuz J, et al. Derivation and validation of a prognostic model for pulmonary embolism. Am J Respir Crit Care Med. 2005;172:1041-6.

6. Jiménez D, Kopecna D, Tapson V, Briese B, Schreiber D, Lobo JL, et al. Derivation and validation of multimarker prognostication for normotensive patients with acute symptomatic pulmonary embolism. Am J Respir Crit Care Med. 2014;189:718-26.

7. Aujesky D, Roy PM, Verschuren F, Righini M, Osterwalder J, Egloff M, et al. Outpatient versus inpatient treatment for patients with acute pulmonary embolism: an international, open-label, randomised, non-inferiority trial. Lancet. 2011;378:41-8.

8. Pennica D, King KL, Shaw KJ, Luis E, Rullamas J, Luoh SM, et al. Expression cloning of cardiotrophin 1, a cytokine that induces cardiac myocyte hypertrophy. Proc Natl Acad Sci USA. 1995;92:1142-6.

9. Pennica D, Swanson TA, Shaw KJ, Kuang WJ, Gray CL, Beatty BG, et al. Human cardiotrophin-1: protein and gene structure, biological and binding activities, and chromosomallocalization. Cytokine. 1996;8:183-9.

10. Caliskan S, Besli F, Yildirim A, Gungoren F, Alisir MF, Polat U, et al. The relationship between cardiotrophin-1 and troponin-i in coronary arterial bypass grafting on the beating heart: a prospective study. Heart Surg Forum. 2015;18:146-50.

11. Kumar BP, Rajasekhar D, Vanajakshamma V. Study of clinical, radiological and echocardiographic features and correlation of Qanadli CT index with RV dysfunction and outcomes in pulmonary embolism. Indian Heart Journal. 2014;66:629-34.

12. González A, López B, Ravassa S, Beaumont J, Zudaire A, Gallego I, et al. Cardiotrophin-1 in hypertensive heart disease. Endocrine. 2012;42:9-17.

13. Konii H, Sato K, Kikuchi S, Okiyama H, Watanabe R, Hasegawa A, et al. Stimulatory effects of cardiotrophin-1 on atherosclerosis. Hypertension. 2013;62:942-50.

14. Ichiki T, Jougasaki M, Setoguchi M, Imamura J, Nakashima H, Matsuoka T, et al. Cardiotrophin-1 stimulates intercellular adhesion molecule-1 and monocyte chemoattractant protein-1 in human aortic endothelial cells. Am J Physiol Heart Circ Physiol. 2008;294:H750-63.

15. Calabrò P, Limongelli G, Riegler L, Maddaloni V, Palmieri R, Golia E, et al. Novel insights into the role of cardiotrophin-1 in cardiovascular diseases. J Mol Cell Cardiol. 2009;46:142-8.

16. Hellenkamp K, Pruszczyk P, Jiménez D, Wyzgał A, Barrios D, Ciurzyński M, et al. Prognostic impact of copeptin in pulmonary embolism: a multicentre validation study. Eur Respir J. 2018;51:1702037. 